\title{
CONE)-(oES
}

CIÊNCIA E TECNOLOGIA

\section{CARACTERIZAÇÃO DOS USUÁRIOS E PARÂMETROS FÍSICO-QUÍMICOS DA ÁGUA ARMAZENADA EM CISTERNAS DO SÍTIO ZABELÊ, NOVA OLINDA - CE}

\author{
Beatriz Dias Pinto, Girlaine Souza da Silva Alencar, \\ Francisco Hugo Hermógenes de Alencar, Francisco Rodrigo de Lemos Caldas, \\ JAQUELINE DOS SANTOS GONÇALVES \\ ${ }^{1}$ Instituto Federal de Educação, Ciência e Tecologia do Ceará (IFCE) \\ Campus de Juazeiro do Norte \\ <beatrizdiazpt@gmail.com>,<girlainealencar@gmail.com> \\ $<$ hugohermogenes@gmail.com>,<rodrigolemosifce@gmail.com> \\ $<$ jaqueline_goncalves@yahoo.com.br> \\ DOI: <https://doi.org/10.21439/conexoes.v14i4.1568>
}

\begin{abstract}
Resumo. O Semiárido brasileiro, caracterizado pela rica biodiversidade do Bioma Caatinga compreende parte da região Nordeste, possui baixas precipitações e altas taxas de evapotranspiração. A escassez hídrica é um dos principais problemas para a população desta região. Para minimizá-lo, a Articulação do Semiárido Brasileiro (ASA), criou o Programa de Formação e Mobilização Social para Convivência com o Semiárido, com a implantação de Cisternas, garantindo o acesso a água em situação de escassez. No Ceará há poucos estudos que assegurem a qualidade da água armazenada. O presente trabalho teve como objetivo caracterizar os usuários e analisar a qualidade da água de cisternas na Zona Rural de Nova Olinda - CE, de acordo com as variáveis físico-químicas da Portaria de Consolidação $\mathrm{n}^{0}$ 5/ 2017. Os dados foram obtidos através de entrevistas, mapas de localização, coleta e análises físico-químicas. Constatou-se que $80 \%$ dos entrevistados possuem renda proveniente da agricultura, $10 \%$ são aposentados e os demais funcionários públicos, do lar e construção civil. A renda mensal da maioria é inferior a um salário mínimo. As cisternas são abastecidas com a água da chuva, carros-pipa e por um sistema de água encanada. Quanto à finalidade da água das cisternas, $74 \%$ para o consumo e suprir as necessidades básicas, como higiene pessoal, lavar louças e roupas. As análises constataram que a água armazenada nas cisternas apresenta níveis toleráveis de potabilidade para os parâmetros de pH, turbidez, dureza, cloretos, ferro, nitrato e sulfato. Entretanto, é necessário que os moradores tomem práticas de conservação, higienização e tratamento da água armazenada.
\end{abstract}

Palavras-chaves: Potabilidade. Perfil Socioeconômico. Semiárido brasileiro.

\section{CHARACTERIZATION OF THE USERS AND PHYSICAL-CHEMICAL PARAMETERS OF THE WATER STORED IN TANKS OF THE SITE ZABELÊ, NOVA OLINDA - CE}

\begin{abstract}
The Brazilian Semiarid, characterized by the rich biodiversity of the Caatinga Biome comprises part of the Northeast region, has low rainfall and high evapotranspiration rates. Water scarcity is one of the main problems for the population of this region. To minimize it, the Brazilian Semi-Arid Articulation (ASA) created the Training and Social Mobilization Program for Living with the Semi-Arid, with the implementation of cisterns, ensuring access to water in situations of scarcity. In Ceará there are few studies that assure the quality of the stored water. The present work aimed to characterize the users and analyze the water quality of cisterns in the rural area of Nova Olinda $-\mathrm{CE}$, according to the physical-chemical variables of Consolidation Ordinance No. 5 / 2017. Data were obtained through interviews, location maps, collection and physicochemical analysis. It was found that $80 \%$ of respondents have income from agriculture, $10 \%$ are retired and the other civil servants, home and construction. The monthly income of most is less than one minimum wage. The cisterns are supplied with rainwater, tankers and a piped water system. As for the purpose of the water of the cisterns, $74 \%$ for consumption and supply the basic needs such as personal hygiene, washing dishes and clothes. The analyzes found that the water stored in the cisterns presents tolerable levels of potability for the parameters of $\mathrm{pH}$, turbidity, hardness, chlorides, iron, nitrate and sulfate. However, it is necessary for residents to practice conservation, sanitation and treatment of stored water
\end{abstract}

Keywords: Potability. Socioeconomic Profile. Brazilian semi-arid 


\section{INTRODUÇÃO}

O Semiárido brasileiro, caracterizado pela rica biodiversidade do Bioma Caatinga, possui precipitações inferiores a $800 \mathrm{~mm}$ anuais, déficit hídrico em pelo menos $60 \%$ do tempo (período de 1970-1990) e Índice de aridez de Thornthwaite (1941) de até 0,50 (ANDRADE; MEIRELES; PALÁCIO, 2010 apud ALENCAR, 2013). Estas características compreende parte da região Nordeste. O período chuvoso concentra-se nos meses de fevereiro a abril (MARENGO, 2011).

Lima e Gessick (2012) apontam os problemas de déficit hídrico como decisivo para o desenvolvimento social e econômico de uma região. Nesse contexto, a implementação de políticas públicas que promovam a descentralização dos recursos hídricos é muito importante para o Semiárido, proporcionando uma melhoria na qualidade de vida da população.

Em 2010 a Organização das Nações Unidas (ONU) por meio da Resolução da Assembleia Geral 64/ 292, "reconhece oficialmente que o acesso à água potável e ao saneamento é um direito humano fundamental, essencial ao pleno gozo da vida (...)" (ONU, 2010).

Um dos grandes desafios do Bioma Caatinga é a escassez hídrica, para esse enfrentamento no ano de 2001 o Governo brasileiro criou o Programa de Formação e Mobilização Social para Convivência com o Semiárido, que passou a ser executado pela Articulação do Semiárido Brasileiro (ASA), por meio de parceria do Ministério do Desenvolvimento Social e Combate à Fome e Agência Nacional das Águas (ANA), que propôs a criação e implantação de Cisternas de Placas como uma tecnologia para solucionar a escassez hídrica, o Programa um Milhão de Cisternas (P1MC) (SCHMITT, 2015).

Após a criação do $\mathrm{P} 1 \mathrm{MC}$ outros programas foram desenvolvidos como "Água para Todos", que integra o "Plano Brasil Sem Miséria”, "Água-Vida", "Programa Uma Terra e Duas Águas $(\mathrm{P} 1+2)$ ", "Programas de cisternas nas escolas", dentre outros. Todos têm como objetivo assegurar e garantir o acesso água em situação de escassez, pois essas tecnologias captam e armazenam a água das chuvas, garantindo o abastecimento da população.

As cisternas são tecnologias inovadoras, desenvolvidas para captar água da chuva, mas podem ser abastecidas por carro-pipa nos períodos de estiagem, minimizando os efeitos da seca no Semiárido. De acordo com os dados do Portal Brasil até o ano de 2016 foram entregues 1,2 milhões de cisternas superando as estimativas proposta inicialmente.

A qualidade da água não se restringe apenas a determinação da pureza, mas também a sua classificação de acordo sua finalidade e aplicação. A sua composição varia de acordo com o meio em que esta está inserida ou até mesmo a partir de substancias que lhes foram inseridas, seja de forma natural ou por atividades humanas. A água é determinada pelas suas características físicas, químicas e biológicas, ondes esses parâmetros são os indicadores de qualidade de água. (Portal Tratamento de Água 2009).

Neste contexto, o monitoramento e a análise da qualidade da água são de extrema importância pois asseguram as condições de vida e saúde da população que tem acesso a este recurso. Os padrões de potabilidade para consumo humano estão determinados pela Portaria de Consolidação $\mathrm{n}^{\circ}$ 5, de 28 de setembro de 2017 (BRASIL, 2017), as formas de tratamento e higienização desses reservatórios interferem na qualidade dessa água, assim há necessidade de conhecer todos esses componentes e padrões.

O presente trabalho teve como objetivo caracterizar os usuários e analisar a qualidade da água de cisternas na Zona Rural de Nova Olinda - CE, de acordo com as variáveis físico-químicas da Portaria de Consolidação $\mathrm{n}^{\mathrm{o}} 5$, de 28 de setembro de 2017.

\section{MATERIAIS E MÉTODOS}

O presente trabalho teve início com um estudo bibliográfico voltado às publicações que retratam o Semiárido e Políticas Públicas que auxiliam no desenvolvimento da região, especificamente, para minimizar os efeitos da seca e o acesso à água.

O trabalho de campo foi desenvolvido com a colaboração da Secretaria de Agricultura do Município de Nova Olinda/CE e da Agente de Saúde responsável pela área da pesquisa, para localizar e conhecer os usuários de Cisternas na área delimitada para o estudo.

O local escolhido para o desenvolvimento do trabalho se deu por ser representativo quanto à realidade do município e possuir fácil acesso e ser próximo ao Laboratório de Química e Saneamento Ambiental (QUIMISAM) do Instituto Federal de Educação, Ciência e Tecnologia do Ceará (IFCE) - Campus Juazeiro do Norte onde as análises foram feitas.

A localização das cisternas foi realizada com o Sistema de Posicionamento Global (GPS) do modelo Etrex Vista H. Posteriormente, utilizou-se o software no Quantum Gis (Q.Gis 2.18.14) para criar um mapa, e o Google Earth para marcar os pontos de coleta de água a serem analisadas.

Foram realizadas 30 entrevistas semiestruturadas com os moradores que possuíam Cisternas de Placas ou de Sistema Calçadão entre os meses de outubro de 2016 e abril de 2017, baseadas nos estudos de ALENCAR. 
2013; MACHADO, 2017), abordando questões relativas a:

\section{Caracterização do Entrevistado:}

- Faixa etária;

- Grau de escolaridade;

- Quantas pessoas por residência;

- Renda Mensal;

- Profissão.

\section{Caracterização das Cisternas:}

- Tipo de cisterna;

- Tempo de uso da cisterna;

- Permanência da estrutura ao longo dos anos;

- Manutenção;

- Higienização das calhas.

\section{Caracterização da Água:}

- Procedência da água;

- Incidência de mosquitos;

- Problemas de saúde;

- Higienização e tratamento da água;

- Captação de água da chuva;

- Finalidade da água;

- Duração da água armazenada.

Após entrevistas, foram realizadas duas coletas aleatórias da água das cisternas nos meses de outubro de 2016 e abril de 2017 em nove pontos diferentes da comunidade, considerando uma distância mínima de 10 metros, para atender uma maior área da comunidade.

As coletas foram feitas diretamente na cisterna ou com auxílio de bomba ou balde. Foram coletados 2 litros de água de cada cisterna e armazenados em frascos estéreis, seguindo o Manual de Análises FísicoQuímicas de Águas de Abastecimento e Residuárias (SILVA; OLIVEIRA, 2001). Posteriormente foram levadas ao Laboratório de Química e Saneamento Ambiental (QUIMISAM) do IFCE/Campus Juazeiro do Norte, para as análises físico-químicas.

As variáveis analisadas foram: $\mathrm{pH}$, turbidez, dureza, cloretos, ferro, nitrato e sulfato, seguindo o método Standard Methods for the Examination of Water and Alpha Wastewater (2012) e padrões estabelecidos pela Portaria de Consolidação 05/ 2017.

Posteriormente os dados foram tabulados no Laboratório de Estudos Ecológicos (LEECO) do IFCE/Campus Juazeiro do Norte.

\section{CARACTERIZAÇÃO DA ÁREA DE ESTUDO}

O Município de Nova Olinda localiza-se ao Sul do estado do Ceará, na região do Cariri. Possui 14.256 habitantes (IBGE, 2010), dos quais 30\% vivem em Zona Rural e mais de 600 famílias são beneficiadas com algum sistema de armazenamento de água (PINTO, 2017).

A pesquisa foi realizada no Sítio Zabelê em Nova Olinda - CE (ver Figura 1). A comunidade possui 72 famílias e todas são beneficiadas com algum Programa do Governo Federal ou Municipal para promover a convivência com o Semiárido.
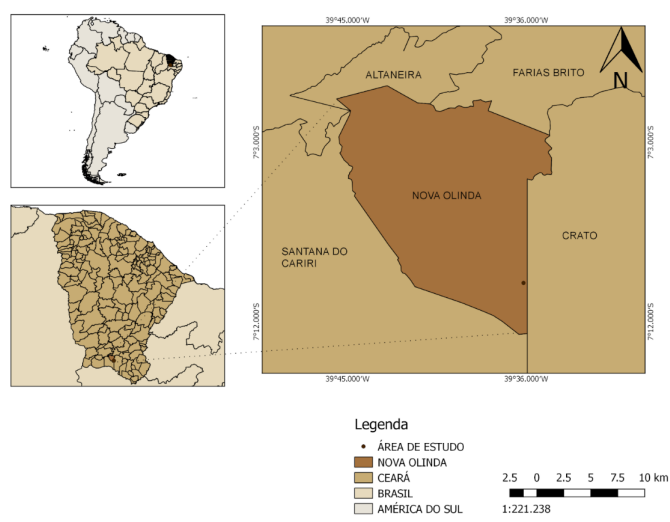

Figura 1: Mapa de localização do Sítio Zabelê em Nova Olinda - CE. Fonte: Autores, Dados: IBGE (2010)

\section{RESULTADOS E DISCUSSÃO}

\subsection{Análises de Dados da Entrevista Semiestrutu- rada}

Das famílias entrevistadas, 80\% são agricultores, $10 \%$ aposentados e os demais são funcionários públicos (3\%), do lar (3\%) e trabalhadores da construção civil (4\%). Esta nova configuração do meio rural também foi constatada por Oliveira (2015), onde moradores da zona rural deslocam-se diariamente para as sedes dos municípios para desenvolver atividades no comércio, setor público e na construção civil, dentre outras. Não ficam restritas apenas ao trabalho rural.

A renda familiar é muito baixa comparada ao salário mínimo que é considerado o valor necessário para a sobrevivência, onde $63 \%$ das famílias tem uma renda 
mensal menor que um salário mínimo e apenas $7 \%$ com 2 a 3 salários mínimos.

O Grau de escolaridade dos usuários entrevistados é considerado baixo, pois apenas $37 \%$ possui Ensino Médio completo e apesar dos esforços governamentais para a erradicação do analfabetismo, 10\% dos entrevistados ainda são analfabetos.

O abastecimento da água das cisternas não é exclusivamente pela água da chuva, e tem diversas fontes, como carro pipa e água encanada, dependendo do período do ano (ver Figura2).
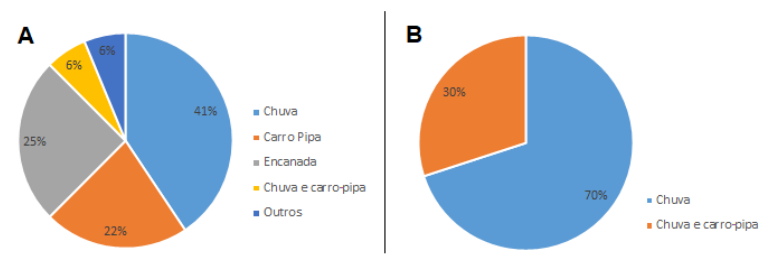

Figura 2: Origem da água armazenada.

A - Mês de outubro de 2016; B - Mês de abril de 2017.

Apesar do longo período de estiagem, muitas cisternas no mês de outubro ainda continuam com a água armazenada no período chuvoso (ver Figura 2-A). Pois os moradores acabam economizando no uso da água.

Quanto a limpeza das cisternas, recomenda-se que a higienização seja realizada semestralmente que é o tempo adequado pois é quando o reservatório se encontra totalmente vazio, porém, a maioria $(77 \%)$ higienizam os reservatórios anualmente e apenas $20 \%$ higienizam semestralmente. O tratamento da água utilizado pelos usuários baseia-se na adição de hipoclorito de sódio e outros métodos para controle de vetores como adicionar piabas nas cisternas, ou não realiza nenhum tipo de tratamento para a água ( ver Figura 3).
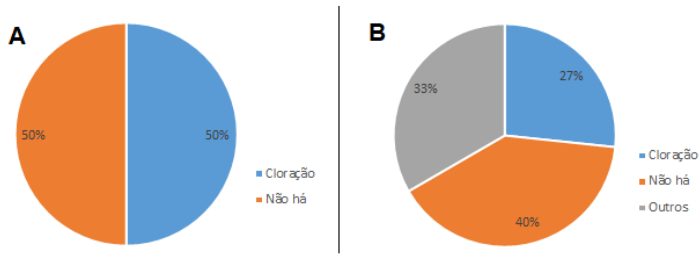

Figura 3: Tipo de tratamento da água armazenada. A - Mês de outubro de 2016; B - Mês de abril de 2017.

De acordo com os estudos de Pinto (2016), a finalidade das cisternas no Semiárido brasileiro é fornecer às famílias água de boa qualidade, destinadas exclusivamente para beber e cozinhar, entretanto todos os entrevistados utilizam para o consumo e suprir as necessidades básicas, como higiene pessoal, lavar louças e roupas, mas também utiliza para outros fins, como para irrigação de hortas e dessedentação de pequenos animais, para aumentar a renda familiar (ver Figura 4).

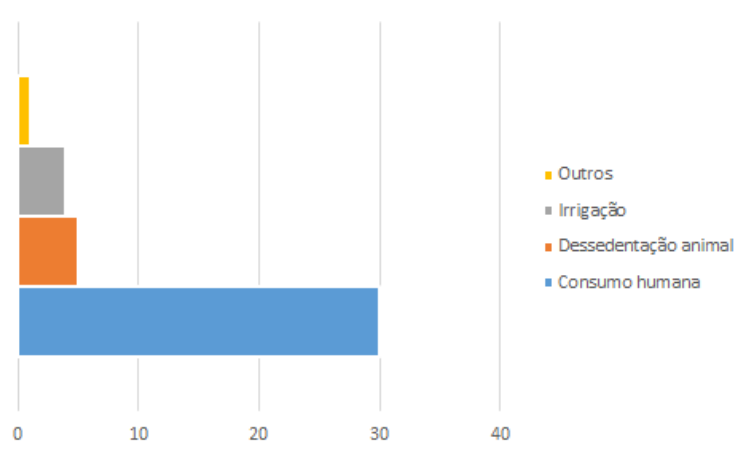

Figura 4: Destinação da água armazenada.

Em relação ao tempo de construção das cisternas, a maioria (47\%) possui menos de 5 anos, mas um número considerável (23\%) possui mais de 10 anos. Pode-se considerar que as estruturas são adequadas para a região pois $60 \%$ das cisternas dos moradores entrevistados, não passaram por nenhum tipo de manutenção. As principais manutenções foram realizadas para reparo de rachaduras, que vem ocasionar as infiltrações e vazamentos.

\subsection{Análises físicas e químicas}

Neste estudo foram analisados parâmetros físicoquímicas para avaliar a qualidade da água de nove pontos do Sítio Zabelê (ver Figura 57. Durante as coletas das amostras de água, foram observadas características dos locais de construção das cisternas e as condições hidrossanitárias.

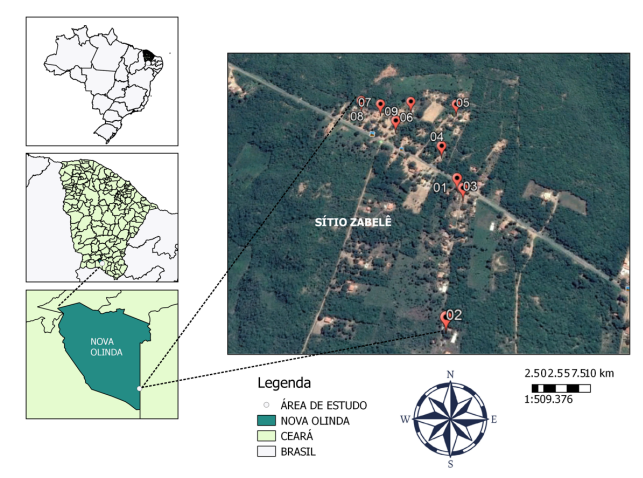

Figura 5: Localização dos pontos de coleta de amostras de água Fonte: Autores, Dados: IBGE 2010) 

ZABELE, NOVA OLINDA - CE

Tabela 1: Resultados das análises físico-químicas da água das cisternas do Sítio Zabelê, em outubro de 2016

\begin{tabular}{|c|c|c|c|c|c|c|c|}
\hline \multirow{2}{*}{ Amostra } & \multicolumn{7}{|c|}{ Variáveis } \\
\cline { 2 - 8 } & $\mathbf{p H}^{1}$ & $\begin{array}{c}\text { Turbidez } \\
\text { (NTU) }^{2}\end{array}$ & $\begin{array}{c}\text { Dureza } \\
(\mathbf{m g C a C O 3 / L )})^{3}\end{array}$ & $\begin{array}{c}\text { Cloretos } \\
(\mathbf{m g} / \mathbf{L})^{4}\end{array}$ & $\begin{array}{c}\text { Ferro } \\
(\mathbf{m g} / \mathbf{L})^{5}\end{array}$ & $\begin{array}{c}\text { Nitrato } \\
(\mathbf{m g} / \mathbf{L})^{6}\end{array}$ & $\begin{array}{c}\text { Sulfato } \\
(\mathbf{m g} / \mathbf{L})^{7}\end{array}$ \\
\hline $\mathbf{1}$ & 5,58 & 0,1 & 1,5 & 0,0086 & 0,054 & 0,636 & 2,93 \\
\hline $\mathbf{2}$ & 5,98 & 0,25 & 3,795 & 0,0238 & 0,426 & 3,14 & 34,8 \\
\hline $\mathbf{3}$ & 7,13 & 0,15 & 16,969 & 0,1779 & 0,123 & 0,761 & 122,32 \\
\hline $\mathbf{4}$ & 7,31 & 0,1 & 10,312 & 0,1044 & 0,077 & 0,044 & 61,44 \\
\hline $\mathbf{5}$ & 7,48 & 0,2 & 9,469 & 0,1116 & 0,022 & 0,479 & 117,59 \\
\hline $\mathbf{6}$ & 7,73 & 0,1 & 1,172 & 0,009 & 0,17 & 0,618 & 3,75 \\
\hline $\mathbf{7}$ & 7,66 & 0,2 & 1,416 & 0,0071 & 0,147 & 0,686 & 4,44 \\
\hline $\mathbf{8}$ & 7,64 & 0,05 & 0,966 & 0,0076 & 0,1 & 0,565 & 4,51 \\
\hline $\mathbf{9}$ & 7,56 & 0,2 & 1,218 & 0,0105 & 0,1 & 0,622 & 4,23 \\
\hline
\end{tabular}

Legenda: Valores máximos permitidos pela Portaria de Consolidação 05/2017- ${ }^{(1)} 6,5-9 ;{ }^{(2)} 5$ NTU; ${ }^{(3)} 500$ mg/L; (4) 250 mg/L; ${ }^{(5)} 0,3$ mg/L; (6) $10 \mathrm{mg} / \mathrm{L}$; (7) $250 \mathrm{mg} / \mathrm{L}$.

A análise da água armazenada em cisternas é de fundamental importância, pois através dos valores encontrados pode-se identificar se atendem os padrões exigidos pela legislação e principalmente prevenir problemas de saúde e possíveis danos a população (LIMA 2014). Os resultados obtidos em laboratório pelas análises físico-químicas estão expostos nas Tabelas 1 e 2 nos meses de outubro de 2016 e abril de 2017, respectivamente. As amostras foram avaliadas de acordo com os padrões de potabilidade da Portaria de Consolidação $\mathrm{n}^{\circ} 5$, de 28 de setembro de 2017.

De acordo com a variável de $\mathrm{pH}$, na Tabela 1 as amostras 1 e 2 encontra-se com concentrações de $\mathrm{pH}$ levemente abaixo do permitido na Portaria. Os demais valores seguem as recomendações da Portaria que determina valores ideais para água de reservatório e consumo 6,0 a 9,5. O pH pode ser determinado pelo gás carbônico dissolvido e pela alcalinidade da água.

O parâmetro de turbidez de acordo com Tabela 1 . notou-se que as amostras de água coletadas das cisternas mostraram que os valores variam de 0,05 a 0,25 UNT. Segundo o Ministério da Saúde, o valor máximo permitido em água potável é de 5 UNT, assim todas as amostras estão dentro do padrão.

Em relação a dureza observado na Tabela 1, as amostras de água coletadas das cisternas mostraram valores de variam de 0,96 a 16,96 mg/L. Assim os valores estão dentro das recomendações da Portaria de Consolidação 05/2017 do MS que determina $500 \mathrm{mg} / \mathrm{L}$, essa propriedade tem a responsabilidade de modificar o sabor da água, onde em grandes concentrações deixam a água salina.

A variável de cloretos como está disposto na Tabela 1. mostraram que os valores de variam de 0,0071 a $0,177 \mathrm{mg} / \mathrm{L}$. Esses valores estão de acordo com as recomendações da Portaria do MS onde determina limite máximo $250 \mathrm{mg} / \mathrm{L}$.

Em relação ao ferro na Tabela 1 a amostra 2 encontra-se com um valor acima do permitido, as demais se no padrão. A portaria determina que seja considerado o valor máximo de $0,3 \mathrm{mg} / \mathrm{L}$ de ferro na amostra.

Em conformidade com a Tabela 1 os valores para nitrato das amostras de água coletadas das cisternas mostraram que os valores de variam de 0,04 a 3,14 mg/L. Todas as amostras estão de acordo com as recomendações da Portaria de Consolidação 05/ 2017 que determina o valor máximo permitido $10 \mathrm{mg} / \mathrm{L}$.

Os valores encontrados nas concentrações de sulfato mostrados na Tabela 1 varia de 2,93 a 122,32 mg/L. Assim as amostras estão dentro do valor permitido da portaria que estabelece $250 \mathrm{mg} / \mathrm{L}$.

A Tabela 2 mostra os resultados obtidos nas coletas e analises desenvolvidas no mês se abril de 2017.

De acordo com o exposto as amostras do mês de abril 2017 encontram-se dentro dos padrões permitidos pela Portaria, onde as variáveis de $\mathrm{pH}$ estão entre 6,7 a 8,39 , turbidez $0,1 \mathrm{NTU}$ a $1,7 \mathrm{NTU}$, dureza $1,76 \mathrm{mg} / \mathrm{L}$ a 8,43 , cloretos $0 \mathrm{mg} / \mathrm{L}$ a $0,059 \mathrm{mg} / \mathrm{L}$, ferro $0,037 \mathrm{mg} / \mathrm{L}$ a $0,055 \mathrm{mg} / \mathrm{L}$, nitrato $0,0196 \mathrm{mg} / \mathrm{L}$ a $0,1602 \mathrm{mg} / \mathrm{L}$ e sulfato variando de $9,75 \mathrm{mg} / \mathrm{L}$ a $33,23 \mathrm{mg} / \mathrm{L}$.

Libânio (2010) mostra que pH causa interferência na solubilidade de determinadas substâncias, consequentemente na sua cor e também define o grau de toxicidade de vários elementos, pode-se observar essas características em variados segmentos na potabilização de água para consumo, temos como exemplo: o abrandamento de águas com dureza elevada, afim de prevenir a corrosão em adutoras, no processo de coagulação de 

ZABELÊ, NOVA OLINDA - CE

Tabela 2: Resultados das análises físico-químicas da água das cisternas do Sítio Zabelê, em abril de 2017

\begin{tabular}{|c|c|c|c|c|c|c|c|}
\hline \multirow{2}{*}{ Amostra } & \multicolumn{7}{|c|}{ Variáveis } \\
\cline { 2 - 8 } & $\mathbf{p H}^{1}$ & $\begin{array}{c}\text { Turbidez } \\
\text { (NTU) }^{2}\end{array}$ & $\begin{array}{c}\text { Dureza } \\
(\mathbf{m g C a C O 3 / L})^{3}\end{array}$ & $\begin{array}{c}\text { Cloretos } \\
(\mathbf{m g} / \mathbf{L})^{4}\end{array}$ & $\begin{array}{c}\text { Ferro } \\
(\mathbf{m g} / \mathbf{L})^{5}\end{array}$ & $\begin{array}{c}\text { Nitrato } \\
(\mathbf{m g} / \mathbf{L})^{6}\end{array}$ & $\begin{array}{c}\text { Sulfato } \\
(\mathbf{m g} / \mathbf{L})^{7}\end{array}$ \\
\hline $\mathbf{1}$ & 6,7 & 0,1 & 1,76472 & 0,0059 & 0,044 & 0,06978 & 9,75 \\
\hline $\mathbf{2}$ & 7,36 & 0,1 & 4,60788 & 0,00298 & 0,0462 & 0,1269 & 30,94 \\
\hline $\mathbf{3}$ & 7,43 & 1,31 & 4,11768 & 0,01292 & 0,0375 & 0,06518 & 17,1 \\
\hline $\mathbf{4}$ & 7,59 & 0,33 & 8,43144 & 0,059627 & 0,0419 & 0,0446 & 33,23 \\
\hline $\mathbf{5}$ & 7,71 & 0,1 & 2,84316 & 0,00298 & 0,0419 & 0,0518 & 12,36 \\
\hline $\mathbf{6}$ & 8,29 & 0,1 & 2,25492 & 0,00298 & 0,044 & 0,0366 & 10,53 \\
\hline $\mathbf{7}$ & 8,39 & 0,1 & 2,74512 & 0,001987 & 0,0419 & 0,0196 & 10,13 \\
\hline $\mathbf{8}$ & 8,04 & 1,7 & 4,4118 & 0 & 0,055 & 0,1602 & 10,53 \\
\hline $\mathbf{9}$ & 8,27 & 0,1 & 2,05884 & 0,010931 & 0,0506 & 0,046 & 10,37 \\
\hline
\end{tabular}

Legenda: Valores máximos permitidos pela Portaria de Consolidação 05/2017- (1) 6,5-9; (2) 5 NTU; ${ }^{(3)} 500$ mg/L; (4) 250 mg/L; ${ }^{(5)} 0,3$ mg/L; (6) $10 \mathrm{mg} / \mathrm{L} ;{ }^{(7)} 250 \mathrm{mg} / \mathrm{L}$.

sais de ferro e alumínio.

A turbidez são pequenas partículas suspensas na água dada pela matéria orgânica e inorgânica divididas, como os fitoplâncton e outros organismos microscópicos plânctons ou não. Define também de forma simples que turbidez é um fator que indica a transparência da água (HELLER; PáDUA, 2010).

Os componentes que formam a dureza da água são principalmente os sais alcalinos terrosos, bem como o cálcio e magnésio, mas também pode ser por outros metais bivalentes com menor intensidades. A dureza em níveis elevados pode causar sabor desagradáveis e diminuir a formação de espumas (ROCHA, 2009).

Os cloretos estão se faz presente em todas as águas naturais, em pequena ou grande quantidade, por origem mineral ou através de contaminação marinha através dos suprimentos subterrâneos, despejos de animais e humanos, os efluentes industriais e contaminação por sais utilizados na agricultura. Os limites para cloretos em águas foram estabelecidos, em função do sabor que ele confere a mesma (Gomes Filho, 2013).

O ferro é conhecido por mudar as propriedades da água, como sabor, odor e cor quando se encontra em concentrações elevadas. Estes metais como o ferro (ver Figura 6) e manganês são originários das rochas, o ferro geralmente está presente em águas naturais, superficiais e subterrâneos de forma solúvel e dissolvida, já o manganês normalmente é encontrado em águas subterrâneas de poços artesianos no fundo de reservatórios, onde há baixas concentrações de oxigênio (LIBâNIO, 2010).

As concentrações de nitrato podem ser de origem natural vinda de rochas ígneas, de áreas de drenagem e da decomposição da matéria orgânica podendo ser intensificadas por esgotos domésticos (HELLER; Pá-

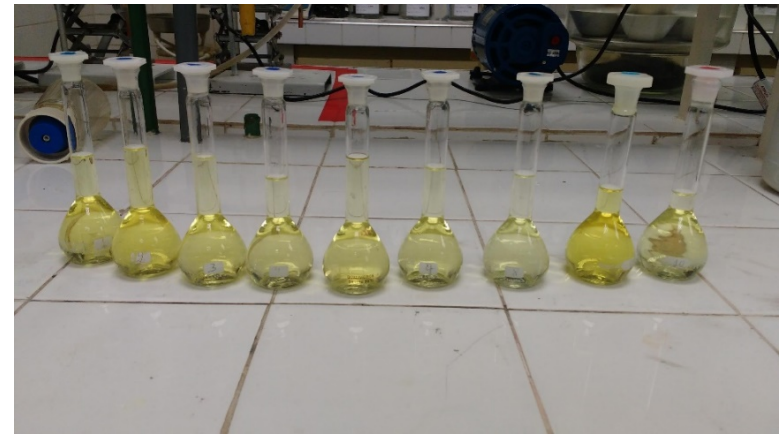

Figura 6: Análise de ferro Fonte: Autores

DUA, 2010).

O sulfato pode surgir nas águas subterrâneas através da dissolução de solos e rochas, como o gesso e o sulfato de magnésio e pela oxidação de sulfeto. Nas águas superficiais, podem surgir através das descargas de esgotos domésticos e efluentes industriais (BRANCO. 2011).

\section{CONCLUSÕES}

As cisternas permitem o armazenamento de água de boa qualidade e de fácil acesso as famílias, melhorando a qualidade de vida dos moradores do Sítio Zabelê do município de Nova Olinda - CE.

As análises realizadas permitem afirmar que água armazenada encontra-se em níveis toleráveis de potabilidade. Entretanto, é necessário que os moradores desenvolvam práticas de conservação, higienização e tratamento, para que a água se mantenha dentro dos parâmetros para consumo humano proposto na Portaria de 
CARACTERIZAÇÃO DOS USUÁRIOS E PARÂMETROS FÍSICO-QUÍMICOS DA ÁGUA ARMAZENADA EM CISTERNAS DO SÍTIO ZABELÊ, NOVA OLINDA - CE

Consolidação ${ }^{\circ}$ 05/ 2017.

A adoção de medidas para melhorar as práticas de conservação destes reservatórios, deve considerar a baixa escolaridade dos moradores, adotando metodologias acessíveis e material de fácil entendimento.

\section{REFERÊNCIAS}

ALENCAR, G. S. d. S. Código de conduta: uma potencialidade para o desenvolvimento sustentável da floricultura do Agropolo Cariri/CE. Tese (Doutorado em Geografia) — Universidade Estadual Paulista (UNESP), Rio Claro - SP, 2013. $161 \mathrm{f}$.

APHA. Standard Methods for the Examination of Water and Alpha Wastewater. 22. ed. Washington D.C.: AMERICAN PUBLIC HEALTH ASSOCIATION, 2012.

BRANCO, C. C. Monitoramento Rio Ribeirão das Lajes - Rio Guandu. 1. ed. Rio de Janeiro: Universidade Federal do Estado do Rio de Janeiro, 2011.

BRASIL. Programa cisternas democratiza acesso à água no Semiárido. 2016. Disponível em: <http: //www.brasil.gov.br/cidadania-e-justica/2016/05/ programa-cisternas-democratiza-acesso-a-agua-no-semiarido

Consolidação das normas sobre as ações e os serviços de saúde do Sistema Único de Saúde. 2017. Portaria $n^{0}$ 05/ 2017. Brasília, DF.

Gomes Filho, R. R. Gestão de Recursos Hídricos: conceitos de experiências em bacias hidrográficas. 1. ed. Goiania: Editora América, 2013.

HELLER, L.; PáDUA, V. L. d. Abastecimento de Água para Consumo Humano. 2. ed. Belo HorizonteMG: Editora UFMG, 2010. v. 2.

IBGE. IBGE cidades. 2010. Instituto Brasileiro de Geografia e Estatística.

LIBâNIO, M. Fundamentos de Qualidade e Tratamento de Água. 3. ed. Campinas SP: Editora Atomo, 2010

LIMA, A. G. P. d. S. Qualidade Sanitária da Água em Cisternas da Mesorregião do Sul Cearense. Dissertação (Trabalho de Conclusão de Curso) nstituto Federal De Educação, Ciência E Tecnologia Do Ceará - Campus Juazeiro do Norte, Juazeiro do Norte, 2014.
LIMA, P. S.; GESSICK, A. Identificação dos tipos de captação de águas pluviais no cariri central-ceará. In: VII CONNEPI. VII CONNEPI-Congresso Norte Nordeste de Pesquisa e Inovação. Palmas - TO, 2012. p. 1-7.

MACHADO, T. T. V. Investigação da qualidade da água nas Cisternas de Placas e polietileno no semiárido paraibano. 2017. Universidade Federal da Paraíba - UFPB-PRODEMA.

MARENGO, J. A. Variabilidade e mudanças climáticas no Semiárido brasileiro. 2011. Instituto Nacional do Semiárido Campina Grande - PB.

OLIVEIRA, I. F. d. Semiárido baiano: a dinâmica contraditória do desenvolvimento. 1 . ed. São Paulo: Baraúna, 2015.

ONU. $\mathrm{O}$ direito humano à água e ao saneamento. 2010. Organização das Nações Unidas. Disponível em: $<$ https://www.un.org/waterforlifedecade/pdf/human_ right_to_water_and_sanitation_media_brief_por.pdf>

PINTO, B. D. Perfil dos usuários de água armazenada em cisternas do semiárido cearense. 2016. I Congresso Internacional Da Diversidade Do Semiárido. Campina Grande - PB.

Perfil socioeconômico dos beneficiários de Cisternas de Placas do Sítio Zabelê, Nova Olinda-CE. 2017. II Congresso Internacional Da Diversidade Do Semiárido. Campina Grande - PB.

Portal Tratamento de Água. Qualidade da Água. 2009. Disponível em: <https://www.tratamentodeagua. com.br/artigo/qualidade-da-agua/ $>$

ROCHA, J. C. Introdução à Química Ambiental. 2. ed. Porto Alegre: Bookman, 2009.

SCHMITT, J. F. A. Adoção de inovações no combate à seca no Semiárido: um estudo com os usuários de cisternas de polietileno nos municípios de Trairi-CE e Caucaia-CE. 2015. Universidade Estadual do Ceará - UECE.

SILVA, S. A.; OLIVEIRA, R. Manual de análises físico-químicas de águas de abastecimento e residuárias. 1. ed. Campina Grande - PB: UFPB, 2001. 